\title{
REGULADORES DE CRESCIMENTO NA PRODUÇÃO DE MANDIOCA ${ }^{(1)}$
}

\author{
ARAKEN SOARES PEREIRA, JOSÉ OSMAR LORENZI (2) e DOMINGOS ANTONIO MON- \\ TEIRO, Seçâo de Raízes e Tubérculos, Instituto Agronómico.
}

\begin{abstract}
RESUMO
Foram conduzidos em Campinas, Estado de São Paulo, dois experimentos de campo com a finalidade de se observar, em mandioca, o efeito de quatro reguladores de crescimento. Num deles, as manivas foram tratadas por imersão com os ácidos giberélico, naftalenoacético e indolacético e vitamina $B_{1}$; os resultados não mostraram äiferenças significativas destes tratamentos na produção de raízes e ramas. No outro experimento em que se avaliou apenas o efeito do ácido giberélico, embora também não tenha havido diferenças significativas na produção de raizes, houve uma tendência geral no aumento da produção, principalmente na concentração de $50 \mathrm{ppm}$, quer para imersão instantânea ou por uma hora das manivas, quer para pulverização das plantas aos três meses de idade.
\end{abstract}

\section{INTRODUÇĀO}

Embora os reguladores de crescimento sejam substâncias conhecidas há bastante tempo e usadas para diversas culturas, a fim de obter vantagens econômicas, seja na produção, seja na qualidade dos produtos, em mandioca, os estudos não são ainda suficientes para perrititir sua reco-

(1) Trabalho apresentado na 33̊ Reunião Anual da S.B.P.C., realizada em Salvador (BA), de 8 a 15 de julho de 1981. Recebido para publicação a 24 de maio de 1983.

(2) Com bolsa de suplementação do CNPq. 
mendação. Todavia, INDIRA \& SINHA (3) verificaram aumento do número de raízes com a aplicação de ácido naftalenoacético (NAA) e efeito inverso para ácido giberélico $\left(\mathrm{GA}_{3}\right)$ e cloreto de 2-cloroetil trimetil amônio (CCC). Diminuição nos teores de ácido cianídrico das raízes, mediante aplicação foliar de reguladores de crescimenio, foi obtida por INDIRA et alii (2) e KURIAN et alii (4). Efeitos positivos na produção de raízes foram conseguidos com a aplicação de ácido 2-cloroetil fosfônico (ETHREL), ácido 2, 3, 5-triiodo benzóico (TIBA) e CCC, segundo SHANMUGAM \& SHANAMUGAVELU (5), SHANMUGAN et alli (6) e DAS GUPTA (1) respectivamente.

Assim, o presente trabalho teve por objetivo investigar o efeito de alguns reguladores de crescimento, em condiçōes de campo, na produção de ramas e raízes tuberosas de mandioca.

\section{MATERIAL E MÊTODOS}

Foram conduzidos dois experimentos de campo, empregando-se, no primeiro: ácido giberélico, ácido naftalenoacético, vitamina $B_{1}$ e ácido indolacético. Esses produtos foram usados na concentracão de 50 ppr: e, sua aplicação, feita mediante imersão total das manivas por um periodo de sete horas. As manivas, com $25 \mathrm{~cm}$ de comprimento, depois de tratadas foram plantadas pelo sistema comum, horizonialmente, em sulcos a $10 \mathrm{~cm}$ de profundidade e cobertas com terra. As jarcelas tiveram dez plantas, em uma única linha, no espaçamento de $2,4 \mathrm{~m} \times 0,8 \mathrm{~m}$ (Quadro 1).

QUADRO 1. Efeito da imersão de manivas em diversos reguladores de crescimento a $50 \mathrm{ppm}$ por sete horas, sobre «stand» final e produçãc de raizes e ramas de mandioca. Colheita aos nove meses de idade das plantas

\begin{tabular}{|c|c|c|c|}
\hline \multirow{2}{*}{ Tratamentos } & \multirow{2}{*}{ «Stand» final } & \multicolumn{2}{|c|}{ Produção } \\
\hline & & Raízes & Ramas \\
\hline & $\%$ & $\mathrm{~kg} / 19,2 \mathrm{~m}^{2}$ & $\mathrm{~kg} / 19,2 \mathrm{~m}^{2}$ \\
\hline 1. Testemunha(1) & 100,0 & 14,8 & 9,6 \\
\hline 2. Testemunha(2) & 100,0 & 14,2 & 8,6 \\
\hline 3. Acido giberélico & 95,0 & $9, \overline{5}$ & 6,4 \\
\hline 4. Acido naftalenoacético & 95,0 & 12,2 & 8,1 \\
\hline 5. Vitamina $B_{1}$ & 100,0 & 10,4 & 6,5 \\
\hline 6. Âcido indolacético & 90,0 & 9,8 & 6,2 \\
\hline F (Tratamento) & $1,15 \mathrm{~ns}$ & $2,27 \mathrm{~ns}$ & $2,37 \mathrm{~ns}$ \\
\hline Coeficiente de variação $(\%)$ & 13,36 & 25,73 & 24,53 \\
\hline
\end{tabular}

(1) Manivas sem nenhum tratamento.

(2) Manivas imersas em água por sete horas. 
No segundo experimento, considerou-se apenas o ácido giberélico, variando a concentração, tempo de imersão e modo de áplicação, conforme descrição dos tratamentos apresentada no quadro 2. As manivas com $30 \mathrm{~cm}$ de comprimento foram plantadas pela base, na posição inclinada e enterradas $15 \mathrm{~cm}$ no solo. As parcelas tiveram cinco plantas, em uma única linha, no espaçamento de $2,5 \mathrm{~m} \times 0,8 \mathrm{~m}$.

Ambos os experimentos foram conduzidos no Centro Experimental de Campinas, Instituto Agronômico, em solo do grande grupo Latossolo Roxo (Typic Euthrorthox). O delineamento estatístico adotado foi de blocos ao acaso com quatro repetiçōes e, a variedade utilizada, a SRT 454-Guaxupé.

\section{RESULTADOS E DISCUSSÃO}

No quadro 1 são apresentados os dados de produção de raízes, ramas e "stand" final e as respectivas análises, resumidas, da variância, do experimento que estudou o efeito da imersão das manivas nos diversos produtos reguladores de crescimento. Verifica-se que, embora não tenha havido diferenças significativas entre os tratamentos, houve uma tendência depressiva na produção de raízes e ramas para todos os produtos utilizados, provavelmente devido ao longo período de imersão.

No quadro 2, encontram-se os dados obtidos do segundo experimento, relativos a concentração, tempo de imersão e modo de aplicação do ácidu giberélico. Os resultados mostraram que não houve difєrenças significativas entre os tratamentos estudados, evidenciando apenas uma tendência geral de aumento de produção de raízes tuberossas quando se empregou o ácido giberélico, principalmente na concentração de $50 \mathrm{pprn}$.

QUADRO 2. Efeito da concentração, tempo de imersão e modo de aplicação de ácido giberélico, sobre «stand» final e produção de raizes de mandioca. Colheita aos 14 meses de idade das plantas

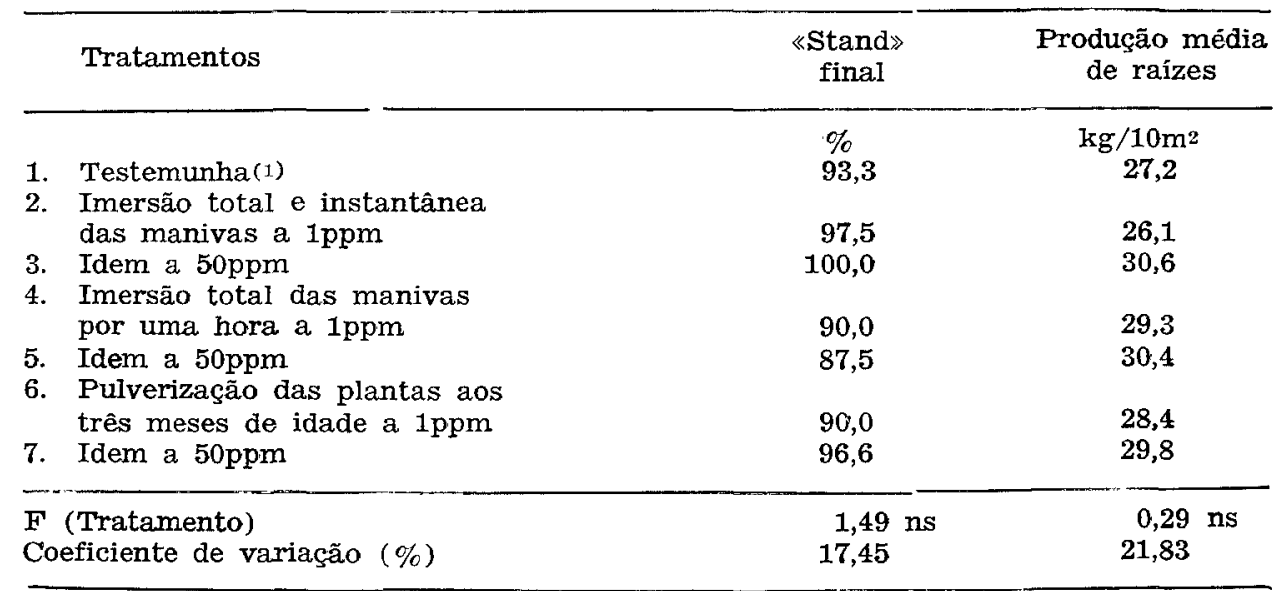

(1) Manivas sem nenhum tratamento. 
De modo geral, a tendência observada de aumento da produção de raízes indica a necessidade de estudos mais profundos e detalhados nessa área de pesquisa, envolvendo, principalmente, o aspecto varietal e uma série maior de produtos químicos reguladores do crescimento.

\section{SUMMARY}

\section{EFFECTS OF SOME GROWTH REGULATORS ON CASSAVA YIELDS}

In two field experiments the effects of gibberellic acid, indoleacetic acid, naphthaleneacetic acid and $B_{1}$ vitamin, were evaluated as growth regulators on cassava. Although the treatments used did not increase the roor and stem yields significantly, gibberellic acid at $50 \mathrm{ppm}$ showed a tendency to increase root yields when the cassava cuttings were immersed instantaneously or during one hour, or when the 3-month old plants were sprayed.

\section{REFERENCIAS BIBLIOGRÁFTCAS}

1. DAS GUPTA, H.P. Effects of cycocel on crop plants in Sierra Leone. II. Cassava (Manihot esculenta Crantz). Experimental Agriculture, 12:321-328, 1976.

2. INDIRA, P.; MAINI, S.B.; MANDAL, R.C. Effect of growth on the cyanogIucoside content in Manihot esculenta Crantz. Current Science, 41(9):339-340, 1972.

3. \& SINHA, S.K. Studies on the initiation and development of tubers in Manihot esculenta Crantz. Indian Journal of Plant Physiology, 13(1): 24-39, 1970.

4. KURIAN, T. et alii. Regulation of the levels of cyanogenie glucosides in cassava (Manihot esculenta Crantz). Journal of Root Crops, $₫(2): 39-43,1976$.

5. SHANMUGAM, A. \& SHANAMUGAVELU, K.G. Influence of ethrel on growih and yield of tapioca. Indian Journal of Plant Physiology, 17(1-2):44-46, 1974.

6. --_; THAMDURAJ, S.; MUTHUKRISHNAN, C.R. Effect of 2, 3, 5-triiodis benzoic acid (TIBA) on tapioca (Manihot esculenta Crantz). Madras Agricultural Journal, 61(10-12):1007-1008, 1974. 